\title{
Determination of Lactose Alone and in the Presence of Sucrose by the Method of Munson and Walker
}

\author{
By Lester D. Hammond
}

\begin{abstract}
The existence of uncertainties in the tables employed in the determination of lactose, alone and in the presence of sucrose, by the method of Munson and Walker has led to the redetermination of the reducing-sugar values from which these tables were calculated. The original tables were based on the weights of cuprous oxide corresponding to various weights of lactose, and in the present paper all values are referred to the weights of copper determined electrolytically. Data showing the magnitude of the contamination of the cuprous oxide under the conditions prevailing in the method are given. The table of Straughn and Given for mixtures of lactose and sucrose in the ratio of $1: 12$ is shown to be in error. From the redetermined values an extensive table of the copper values for lactose and for two ratios of lactose and sucrose has been computed.
\end{abstract}

\section{Introduction}

The estimation of lactose is of considerable importance to the dairy industry, to other processors of food, and to the State and Federal Governments. The interest of the latter is indicated by the fact that the determination of lactose is listed in the Book of Methods of the Association of Official Agricultural Chemists.

This paper is a report of the results obtained by the redetermination of the copper values of lactose and two of its mixtures with sucrose by the unified method of Munson and Walker. This method, published in $1906[1],{ }^{1}$ has found wide acceptance because of its simplicity and reproducibility of results. However, the original tables are based on the weight of cuprous oxide obtained rather than on the procedure of the direct determination. of metallic copper or of other accepted methods. In addition, there exists evidence that there are other errors in these tables.

The original Munson and Walker table consisted of weights of dextrose, invert sugar, and two mixtures of invert sugar and sucrose corresponding to various weights of cuprous oxide. In 1907 Walker [2] extended the applicability of

1 Figures in brackets indicate the literature references at the end of this paper. the method to include both lactose and maltose. Subsequently, an error in the calculation of the lactose table was discovered, and a corrected table was published [3] in 1912. In this same year Given published [4] a book of methods of sugar analysis in which he stated that a question had arisen as to the composition of the lactose prepared by Walker. He further stated that "Mr. M. N. Straughn of the Sugar Laboratory, Bureau of Chemistry, U. S. Dept. of Agric. has prepared a pure sugar and made the determinations for a new table for lactose, and with the assistance of the author has made the calculations for that table and, in addition, the determinations and calculations for a table for a mixture of 1 part lactose and 4 parts sucrose for use on condensed milks, and for 1 part lactose and 12 parts sucrose for use on milk chocolates. In all cases the work was done on lactose of the formula $5\left(\mathrm{C}_{12} \mathrm{H}_{22} \mathrm{O}_{11}\right)+$ $2\left(\mathrm{H}_{2} \mathrm{O}\right)$, and calculated to the hydrated form $\mathrm{C}_{12} \mathrm{H}_{22} \mathrm{O}_{11}+\mathrm{H}_{2} \mathrm{O}$." As far as can be ascertained, this direct quotation from Givens' book is the only record of this work extant. No statement was made as to the method of preparing the lactose, no analytical data were given, nor did the author state the method of determining copper, which, presumably, was weighed as $\mathrm{Cu}_{2} \mathrm{O}$ in the manner followed by Munson and Walker. As 
this table for lactose and its mixtures with sucrose is official with the Association of Official Agricultural Chemists, it seemed desirable to carry out a complete redetermination on the basis of the copper values rather than on the basis of weights of cuprous oxide.

\section{Preparation of Lactose}

Walker prepared his sample of lactose by pouring a hot aqueous solution of the recrystallized sugar into alcohol, with constant stirring. The fine crystals that separated were first dried in air and then over anhydrous calcium chloride. From a moisture determination according to the method of Brown, Morris, and Millar [5] on the dried purified sample, Walker concluded that the composition of his preparation was $\mathrm{C}_{12} \mathrm{H}_{22} \mathrm{O}_{11} \cdot 1 / 2 \mathrm{H}_{2} \mathrm{O}$. This conclusion was further supported by a determination of carbon and bydrogen. $\mathrm{He}$ reported the specific rotation of his material to be $52.93^{\circ}$, but did not specify the concentration, temperature, or wavelength. Von Lippman [6] states that lactose prepared in the manner described above has the composition $5 \mathrm{C}_{12} \mathrm{H}_{22} \mathrm{O}_{11}$. $2 \mathrm{H}_{2} \mathrm{O}$. Quisumbing and Thomas [7] prepared lactose by adding equal volumes of alcohol and ether to a cold aqueous solution of sugar. They report moisture (loss at $125^{\circ}$ to $130^{\circ}$ ) 5.22 percent, ash 0.03 percent and $[\alpha]_{D}^{25}=52.90^{\circ}$. Lane and Eynon [8] prepared lactose by recrystallizing a pure commercial sample twice from water and found the specific rotation to be $52.5^{\circ}$. Bertrand [9] recrystallized lactose five times from an aqueous solution and found $[\alpha]_{D}^{19}=54.5^{\circ}$. He declared the sample to be $\mathrm{C}_{12} \mathrm{H}_{22} \mathrm{O}_{11} \cdot \mathrm{H}_{2} \mathrm{O}$. Schmoeger [10] showed that the specific rotation of lactose hydrate for $\mathrm{c}=2.372$ to 41.536 was independent of the concentration and from a mean of 70 determinations found that $[\alpha]_{D}^{20}=52.53^{\circ}$. This value was confirmed by Deniges and Bonvans [11] as well as by Parcus and Tollens [12] and it is the value reported in NBS Circular C440. On the contrary, Bacharach [13] determined the value $52.42^{\circ}$, which agrees with the value given by Grossman and Bloch [14]. Hudson [15] has demonstrated that lactose prepared by precipitating with alcohol is not a definite compound, but that it is a mechanical mixture of the hydrated and anhydrous forms. Given and Walker state that their analytical work was done on lactose having a known formula, and that the results were calculated to $\mathrm{C}_{12} \mathrm{H}_{22} \mathrm{O}_{11} \cdot \mathrm{H}_{2} \mathrm{O}$. Quisumbling and Thomas made no statement as to the composition of their preparation. They gave its physical constants, apparently regarded it as the monohydrate, and reported their analytical results on that basis. However, from the work of Hudson it seems possible that the differences in the specific rotation values of these various preparations were due to differences in the amount of water of hydration.

The lactose used in this work was prepared from U. S. P. lactose. A hot 50-percent solution was treated with vegetable char and filtered. Aluminum hydroxide was then added, the solution filtered, and the filtrate was crystallized while in motion. This material was then twice recrystallized under the following conditions. A 50-percent solution was made by heating to $80^{\circ} \mathrm{C}$. The temperature was maintained around this point to prevent the formation of $\beta$-lactose, which is stable above $93^{\circ} \mathrm{C}$. "The solution was crystallized in motion while cooling it to room temperature. The mother liquor was separated from the crystals by means of a centrifuge, and the crystals were washed with water at $5^{\circ} \mathrm{C}$ and dried at room temperature. The lower part of a desiccator was filled with a large portion of the dried material, and a working sample of the lactose was stored over it. The desiccator was kept in a room at $20^{\circ} \mathrm{C}$. At the same time, a small weighed sample of the lactose was placed in the desiccator and kept exposed to its atmosphere. This sample has remained at constant weight over a period of months. Analysis showed the preparation to contain: moisture, ${ }^{2}$ 5.05 percent; ash, 0.003 percent; and $[\alpha]_{D}^{20}(\mathrm{c}=$ $6.9779)=52.54^{\circ}$. These data indicate that the material is lactose monohydrate, $\mathrm{C}_{12} \mathrm{H}_{22} \mathrm{O}_{11}: \mathrm{H}_{2} \mathrm{O}$.

\section{Contamination of Cuprous Oxide}

It has long been known that $\mathrm{Cu}_{2} \mathrm{O}$, produced by the action of impure solutions of reducing sugar, such as sugar-house products, is contaminated with organic and inorganic impurities. It is not so generally appreciated, however, that $\mathrm{Cu}_{2} \mathrm{O}$, formed by the reducing action of solutions of pure sugars, is contaminated with organic impurities, for the

2 McDonald and Turcotte [16] have recently completed an extensive study of $\boldsymbol{\alpha}$-lactose hydrate, in which they determined the loss of weight in vacuo at $80^{\circ}, 120^{\circ}$, and $130^{\circ} \mathrm{C}$. The curves show that this hydrate contains 5 percent of water of hydration. However, they observed a slight variation in the total loss of weight and in the discoloration of the sample with change in time and temperature. 
statement is commonly found in the literature that copper should be weighed as $\mathrm{Cu}_{2} \mathrm{O}$ only when pure sugars are involved. Before Munson and Walker [1] expressed the results of their work in terms of the weight of $\mathrm{Cu}_{2} \mathrm{O}$, the senior author [17] made a series of determinations on solutions of an unidentified reducing sugar in which series the copper was determined electrolytically and as $\mathrm{Cu}_{2} \mathrm{O}$. $\mathrm{He}$ obtained differences between the two sets that varied between -1.2 and $+1.8 \mathrm{mg}$. A surprising thing about these differences is the fact that in a series of 29 copper determinations, the results from the electrolytic set were higher than those weighed as $\mathrm{Cu}_{2} \mathrm{O}$ in 18 determinations, three sets giving identical weights. Munson states that a portion of the differences can be attributed to the loss of weight of the Gooch crucibles caused by the solvent action of Soxhlet's reagent on the asbestos. No details of the work are given and it may be surmised that, during the electrolysis, the current density may have been such that the deposit of copper was oxidized. Munson concluded from this work, however, that copper could be determined as $\mathrm{Cu}_{2} \mathrm{O}$ when solutions of pure sugar were used.

Shortly after the publication of Munson and Walker's work, Zerban and Naquin [18], using a solution of invert sugar and the Munson and Walker method, compared the copper values calculated from the weights of $\mathrm{Cu}_{2} \mathrm{O}$ and $\mathrm{CuO}$ with the corresponding values determined by Low's volumetric iodide method. The results from the $\mathrm{CuO}$ and volumetric sets were practically identical but were $2 \mathrm{mg}$ lower than those from $\mathrm{Cu}_{2} \mathrm{O}$. This difference they attributed to incomplete drying of the $\mathrm{Cu}_{2} \mathrm{O}$. They used the Monroe crucible [19] and thus missed the visual evidence of the contamination of the $\mathrm{Cu}_{2} \mathrm{O}$ by organic decomposition products, which is readily observed in a porcelain crucible when the $\mathrm{Cu}_{2} \mathrm{O}$ is treated with nitric acid.

When the reducing sugar values of the Munson and Walker method were redetermined by the author [20] and compared with the original ones, it was noted that differences existed between the two sets of data that were greater than any that could be attributed to probable experimental error. Jackson and McDonald [21] made a comprehensive study of these differences and showed that the amount of contamination of the $\mathrm{Cu}_{2} \mathrm{O}$ was almost exactly equal to the differences between the copper values of Munson and Walker and the newly deter- mined ones. They also emphasized that the copper that is reduced should not be determined by weighing it as cuprous oxide. It seemed desirable to investigate the extent of the contamination of the cuprous oxide when lactose and mixtures of lactose and sucrose are evaluated.

Determinations of various concentrations of lactose and its mixtures with sucrose were made by weighing the copper as $\mathrm{Cu}_{2} \mathrm{O}$, then dissolving it in nitric acid and determining the copper electrolytically. The data in table 1 are the differences between the value of the copper calculated from the weight of $\mathrm{Cu}_{2} \mathrm{O}$ and the value of the copper determined electrolytically. In all cases, the value of the electrolytic copper is the smaller and, as is to be expected, the differences increase with increasing concentrations of sugar. This effect is much less pronounced with lactose, however, than with its sucrose mixtures.

\begin{tabular}{|c|c|c|c|}
\hline \multirow{2}{*}{$\begin{array}{l}\text { Weight of } \\
\text { lactose } \cdot \mathrm{H}_{2} \mathrm{O}\end{array}$} & \multirow{2}{*}{ Lactose $\cdot \mathrm{H}_{2} \mathrm{O}$} & \multicolumn{2}{|c|}{ Lactose $\cdot \mathrm{H}_{2} \mathrm{O}$ and sucrose } \\
\hline & & $\begin{array}{l}1 \text { lactose } \\
4 \text { sucrose }\end{array}$ & $\begin{array}{l}1 \text { lactose } \\
12 \text { sucrose }\end{array}$ \\
\hline $\begin{array}{r}m g \\
60\end{array}$ & $m g$ of $\mathrm{Cu}$ & $m g$ of $\mathrm{Cu}$ & $m g$ of $\mathrm{Cu}$ \\
\hline 100 & (n) & 0.1 & .5 \\
\hline 140 & ........... & .7 & ............ \\
\hline 150 & - & ........... & 2.1 \\
\hline 200 & 0.1 & 1.3 & 3.3 \\
\hline 240 & - & 1.9 & - \\
\hline 250 & .4 & .......... & 4. 9 \\
\hline 300 & .6 & 2.8 & - n..... \\
\hline 305 & - n. & -.......... & 7.5 \\
\hline 340 & ........... & 3.8 & 9.1 \\
\hline 350 & .8 & ........... & n. \\
\hline
\end{tabular}

\section{Analytical Procedure}

The basic conditions of the determination as given by Munson and Walker were followed. The Soxhlet reagent contained $34.639 \mathrm{~g}$ of $\mathrm{CuSO}_{4} .5 \mathrm{H}_{2} \mathrm{O}$ in $500 \mathrm{ml}$ and $173 \mathrm{~g}$ of potassium sodium tartrate $\left(\mathrm{KNaC}_{4} \mathrm{H}_{4} \mathrm{O}_{6} .4 \mathrm{H}_{2} \mathrm{O}\right)$ and $50 \mathrm{~g}$ of sodium hydroxide in $500 \mathrm{ml}$. The sucrose used was National Bureau of Standards Standard Sample 17. The preparation and properties of the lactose used have been given in detail above. All solutions were measured at $20^{\circ} \mathrm{C}$.

In the original method, the solution was heated over a gas flame, but in this work electrical beating was substituted. The heater was of such a type that the solution in the beaker was practi- 
cally surrounded by the heating element and the current was controlled by means of a constantvoltage regulator and a variable ratio transformer. The solution could be brought to boiling in the required time within \pm 5 sec.

The determinations were made as follows: $50 \mathrm{ml}$ of the solution containing lactose was transferred to a $400-\mathrm{ml}$ beaker containing $50 \mathrm{ml}$ of the mixed Soxhlet reagent. The solution was heated to the boiling point in $4 \mathrm{~min}$ and then allowed to boil 2 min longer. The cuprous oxide was transferred immediately to a Gooch crucible and washed with water at $60^{\circ} \mathrm{C}$. It was then dissolved by adding $5 \mathrm{ml}$ of $1: 1$ nitric acid, and the crucible was quickly covered. Before the addition of the acid a small quantity of water was added to the crucible to minimize the ebullition of nitric oxides. The copper nitrate and washing were received in a $250-\mathrm{ml}$ beaker to which $10 \mathrm{ml}$ of the $1: 1$ nitric acid and about $5 \mathrm{~g}$ of ammonium sulfate had been added. Sufficient water was added to cover the cylindrical platinum-gauze electrodes, the total volume of electrolyte being about $180 \mathrm{ml}$. The electrolysis was conducted overnight at room temperature and at an approximate current density of $0.10 \mathrm{amp} / \mathrm{dm}^{2}$. Upon completion of the deposition, the electrolyte was replaced by distilled water before the circuit was broken. The copper was washed with alcohol, dried $15 \mathrm{~min}$ at $100^{\circ} \mathrm{C}$, cooled in a desiccator, and then weighed. All deposits were bright and showed no evidence of oxidation. ${ }^{3}$

The copper values given in table 2 are the average of four aliquots from one solution of a given concentration. Sugar concentrations above and below those employed in good analytical procedure were included in order to establish the direction of the curve for the whole range of concentrations and particularly in the region where the concentration of copper in the reacting mixture becomes diminishingly small.

\section{Calculation of Results and Sugar Tables}

An examination of the experimental data shown in table 2 shows that a modified equation for the rectangular hyperbola will fit the data satis-

\footnotetext{
${ }^{3}$ In determining the copper values upon which to base the table, the electrolytic method of estimating copper was selected because of its extreme accuracy. In the routine analysis of products containing lactose, any of the conventional methods of determining copper may be used.
}

TABle 2. Experimental data

\begin{tabular}{|c|c|c|c|}
\hline \multirow{3}{*}{$\begin{array}{l}\text { Weight of } \\
\text { lactose. } \mathrm{H}_{2} \mathrm{O} \\
\text { taken }\end{array}$} & \multicolumn{3}{|c|}{ Weight of $\mathrm{Cu}$ found } \\
\hline & \multirow{2}{*}{ Lactose. $\mathrm{H}_{2} \mathrm{O}$} & \multicolumn{2}{|c|}{ Lactose. $\mathrm{H}_{2} \mathrm{O}$ and sucrose } \\
\hline & & $\begin{array}{l}1 \text { lactose } \\
4 \text { sucrose }\end{array}$ & $\begin{array}{l}1 \text { lactose } \\
12 \text { sucrose }\end{array}$ \\
\hline$m g$ & $m g$ & $m g$ & $m g$ \\
\hline 10 & 12. 6 & . . . . & . \\
\hline 20 & 25.8 & 26.5 & 28. 2 \\
\hline 40 & 52.5 & 52.9 & 57.0 \\
\hline 60 & 78.2 & 79.9 & 85. 2 \\
\hline 80 & 104.3 & 106.8 & 112.9 \\
\hline 100 & 129.6 & 133.2 & 140.3 \\
\hline 120 & 156.4 & 160.0 & 167.9 \\
\hline 140 & 182.4 & 185.5 & 194.5 \\
\hline 160 & 207.8 & 211.9 & 220.9 \\
\hline 180 & 232.7 & 237.7 & 247.4 \\
\hline 200 & 259.5 & 263.6 & 274.5 \\
\hline 220 & 285.2 & 289.8 & 300.8 \\
\hline 240 & 309.9 & 315.8 & 326.9 \\
\hline 260 & 335.9 & 342.5 & 352.8 \\
\hline 280 & 361.0 & 366.7 & 377.7 \\
\hline 300 & 385.2 & 391.5 & 403.5 \\
\hline 320 & 409.8 & 416.4 & 428.3 \\
\hline 340 & 435.4 & 439.3 & 439.3 \\
\hline 360 & 439.6 & 439.8 & 439.7 \\
\hline
\end{tabular}

factorily. The equation

$$
(a+x)(b-y)=c+d\left(y_{1}-y\right)^{-1}
$$

is formed by adding the term $\left(d\left(y_{1}-y\right)^{-1}\right.$ to the equation for the rectangular hyperbola and was developed by J. B. Saunders of this Bureau in connection with previous work of the author [20]. In this equation, $x$ equals milligrams of sugar and $y$ equals milligrams of copper. As the concentration of sugar increases, the curve bends more and more away from the copper ordinate, and the added term allows the curve to approach the limiting value of copper in the reagent, $y_{1}=440.9$ $\mathrm{mg}$, asymptotically. The applicability of the Munson and Walker method is questionable for concentrations of sugar corresponding to values of copper greater than approximately $395 \mathrm{mg}$, and it probably would be more desirable to limit the maximum sugar concentration of determinations within a range of about 200 to $250 \mathrm{mg}$ in $50 \mathrm{ml}$.

From the average result of each series of determinations as shown in table 2 , the constants of eq 1 were calculated and adjusted by the method of averages, and the values of the adjusted constants are given in table 3. 
TABLE 3. Values of equation constants

\begin{tabular}{|c|c|c|c|}
\hline \multirow{2}{*}{ Constants } & \multirow{2}{*}{ Lactose. $\mathrm{H}_{2} \mathrm{O}$} & \multicolumn{2}{|c|}{$\begin{array}{l}\text { Lactose. } \mathrm{H}_{2} \mathrm{O} \text { and sucrose } \\
\text { mixtures }\end{array}$} \\
\hline & & $\begin{array}{l}1 \text { lactose } \\
4 \text { sucrose }\end{array}$ & $\begin{array}{l}1 \text { lactose } \\
12 \text { sucrose }\end{array}$ \\
\hline$a_{\ldots-}$ & $16,922.8$ & $11,123.61$ & $5,504.99$ \\
\hline$b_{\ldots} \ldots$ & $22,207.2$ & $14,979.37$ & $7,812.13$ \\
\hline$c \ldots$ & $375,810,000$ & $166,628,790$ & $43,001,550$ \\
\hline$d_{\ldots} \ldots$ & 492,005 & 246,657 & 176,400 \\
\hline
\end{tabular}

Solving eq 1 for $x$ it becomes

$$
x=\frac{c+d\left(y_{1}-y\right)^{-1}}{b-y}-a,
$$

where $x$ equals milligrams of sugar, $y$ equals milligrams of copper and $y_{1}$ equals 440.9 , the amount of copper in milligrams in $50 \mathrm{ml}$ of the alkaline tartrate copper reagent. The number of significant figures retained in the parameters was found sufficient to eliminate any significant computational errors in table 7 .

Table 4 shows the differences between the experimental values and those computed from eq 2 . For the whole range of experimental points in the determination of lactose and of its mixtures with sucrose, the mean differences are fairly small. However, considering the practical working range of the method not to exceed $280 \mathrm{mg}$ of sugar, the differences between the experimental and computed values become $0.2 \mathrm{mg}$ each for the three sets of determinations.

In table 5 are shown the differences in terms of milligrams of copper between the tables of Walker and those of Straughn and Given and the data in table 7. The comparisons are made for various increments of lactose, as shown in column 1 . The data of Straughn and Given are from table 78 of NBS Circular C440, which had been calculated to copper from the original values reported. in weights of $\mathrm{Cu}_{2} \mathrm{O}$. They were then corrected for the organic impurities in the $\mathrm{Cu}_{2} \mathrm{O}$ by means of a graph constructed from data in table 1. For lactose and its mixture with sucrose in the ratio of $1: 4$, the differences between the various sets are moderate, but the differences given in column 5 are greater than could reasonably be attributed to differences caused by experimental errors. As shown in column 5 , the difference for the concentration of $40 \mathrm{mg}$ of lactose is about the same as the others, but as the sugar concentration increases the differences become correspondingly larger. Since there is no record of the work of Straughn and Given other than their table of copper and

TABLE 4. Differences between the experimental and computed values

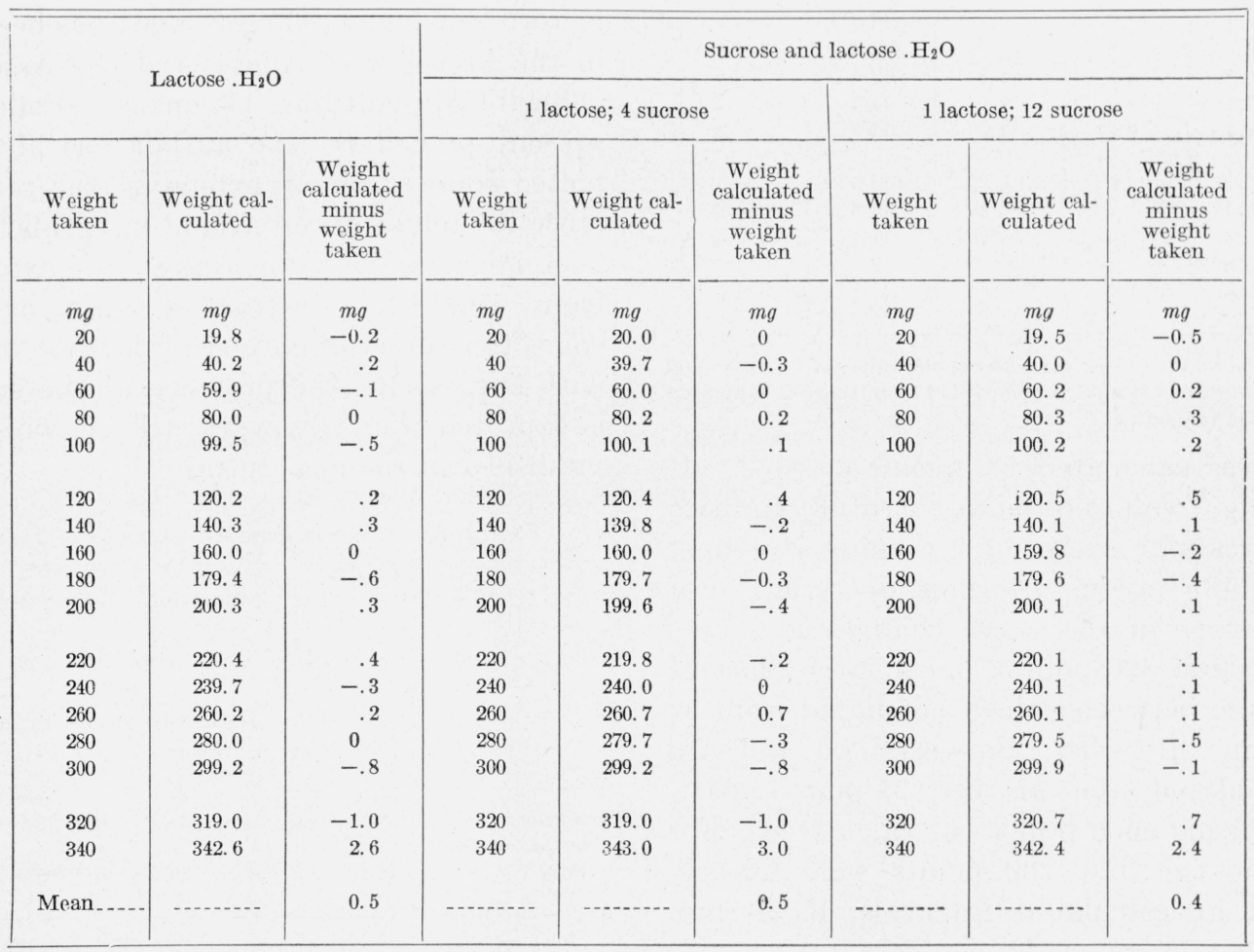


sugar equivalents, any explanation of the cause of these differences must be speculative. However, if their lactose is considered to be anhydrous and their concentrations calculated to the hydrate, the differences between the copper values of the recalculated concentrations and those in table 7 are much smaller and are given in column 6 . They are on the order of the other differences shown in this table. It can only be surmised that, due to some inadvertence, the Straughn and Given copper equivalents for the mixture of lactose and sucrose in the ratio of $1: 12$ are those for the anhydrous form instead of those for lactose monohydrate.

$\mathrm{T}_{\mathrm{ABLE}} 5$. Differences between the various lactose tables

\begin{tabular}{|c|c|c|c|c|c|}
\hline \multirow[b]{3}{*}{$\begin{array}{l}\text { Weight } \\
\text { lactose } \\
. \mathrm{H}_{2} \mathrm{O}\end{array}$} & \multicolumn{5}{|c|}{ Copper values } \\
\hline & \multicolumn{2}{|c|}{ Lactose $\cdot \mathrm{H}_{2} \mathrm{O}$} & \multicolumn{3}{|c|}{ Sucrose and lactose. $\mathrm{H}_{2} \mathrm{O}$} \\
\hline & $\begin{array}{l}\text { Walker } \\
\text { minus } \\
\text { Ham- } \\
\text { mond }\end{array}$ & $\begin{array}{c}\text { Straughn- } \\
\text { Given } \\
\text { minus } \\
\text { Ham- } \\
\text { mond }\end{array}$ & \begin{tabular}{|c|}
1 lactose \\
4 sucrose \\
(Straughn- \\
Given \\
minus \\
Ham- \\
mond)
\end{tabular} & $\begin{array}{c}1 \text { lactose } \\
12 \text { sucrose } \\
\text { (Straughn- } \\
\text { Given } \\
\text { minus } \\
\text { Ham- } \\
\text { mond) }\end{array}$ & $\begin{array}{c}1 \text { lactose } \\
\text { 12 sucrose } \\
\text { (Straughn- } \\
\text { Given } \\
\text { (corrected) } \\
\text { minus } \\
\text { Ham- } \\
\text { mond) } \mathrm{s}\end{array}$ \\
\hline$m g$ & $m g$ & $m g$ & $m g$ & $m g$ & $m g$ \\
\hline 40 & 2.8 & 2.1 & 2. 7 & 2. 3 & -...... \\
\hline 60 & 2.4 & 2. 0 & 2.7 & 4. 3 & -0.1 \\
\hline 80 & 1.8 & 1.9 & 2.8 & 6.1 & .3 \\
\hline 100 & 1.4 & 1.7 & 2.6 & 7. 9 & .7 \\
\hline 120 & 1.0 & 1. 7 & 2.4 & 9.4 & .9 \\
\hline 140 & 0.5 & 1.5 & 2.1 & 10. 9 & 1.0 \\
\hline 160 & 0 & 1.5 & 1.9 & 12. 2 & 1.0 \\
\hline 180 & -0.5 & 1.3 & 1.8 & 13.4 & 0.8 \\
\hline 200 & -1.0 & 1. 2 & 1.3 & 14.3 & .7 \\
\hline 220 & -1.7 & 0.9 & 1.0 & 15.3 & 3 \\
\hline 240 & -2.3 & .9 & 0.6 & 15.9 & -.1 \\
\hline 260 & -2.7 & .5 & .3 & 16. 5 & -.9 \\
\hline 280 & -3.3 & .4 & -.2 & 17.1 & -1.1 \\
\hline 300 & -3.8 & .4 & -.7 & 17. 7 & -1.7 \\
\hline 320 & -3.8 & .7 & -.6 & - n & -1.2 \\
\hline
\end{tabular}

a This column shows the differences between the values of Straughn and Given and those of table 7 when it is assumed that their lactose is anhydrous and when calculated to hydrate.

Table 7 was calculated by means of eq 2 . It shows the sugar values of lactose hydrate and two of its mixtures with sucrose for weights of copper from 10 to $435 \mathrm{mg}$ in intervals of $1 \mathrm{mg}$. For lactose the slope of the curve changes so slowly that, for the first 300 points, linear interpolations could be made between values calculated from eq 2 at 50-point intervals. Between 300 and 375 $\mathrm{mg}$, the calculated intervals were 25 points apart, and from $375 \mathrm{mg}$ each point was calculated. For the $1: 4$ ratio the first 200 points were linearly interpolated at calculated intervals of $50 \mathrm{mg}$; from 200 to $375 \mathrm{mg}$ of copper each tenth point was calculated and thence each point. For the 1:12 mixture each tenth point between 100 and $375 \mathrm{mg}$ was calculated, as well as each individual point after $375 \mathrm{mg}$.

\section{General Discussion}

Since there is no stoichiometrical relation between the reacting compounds in a determination of reducing sugar by the use of Soxhlet's reagent, it follows that all such determinations must be empirical. In order to utilize these reactions as a quantitative analytical method, it is necessary that all procedures and conditions be standardized and to observe rigidly all such conditions of the method when making a determination. Then, in order to be able to interpret the results, it is required that certain data accompany the method. They are usually given in the form of a table, such as table 7 . In its present form this table has a limited use. Although the Straughn-Given table was published in 1912, no proposal was made to widen its use until 1930 when White [22] published a graph constructed from the data in this table. In 1932 Fitelson [23] also published a graph based on that of White's to which he added an additional curve and extrapolated all the curves to include the $16: 1$ ratio of sucrose to lactose, and since 1935 this chart has been included in the Methods of Analysis of the Association of Official Agricultural Chemists. Following the present procedure, the author has already completed some work of extending the ratios of sucrose to lactose in convenient intervals from $2: 1$ to $20: 1$, inclusive, so as to secure more extended data from which to construct a chart or table for correcting determinations of lactose in mixtures with sucrose for the presence of the sucrose. It is expected that this work will be completed and published in the near future.

TABLE 6. Comparison with results of Hammond

\begin{tabular}{|c|c|c|c|c|c|c|c|c|}
\hline & \multicolumn{8}{|c|}{ Milligrams of lactose taken } \\
\hline & 20 & 40 & 50 & 100 & 150 & 200 & 260 & 300 \\
\hline & \multicolumn{8}{|c|}{ Milligrams of copper found } \\
\hline Hammond ....... & 25.8 & 52.5 & & 129. 6 & & 259.5 & 335.9 & 385.2 \\
\hline Brewster.......... & 25.7 & 52.6 & 65.5 & 130.4 & 194.8 & 259.4 & 335.4 & 386.2 \\
\hline $\begin{array}{l}\text { Computed from } \\
\text { table } 7\end{array}$ & 26.1 & 52.3 & 65.3 & 130.3 & 194.7 & 259.1 & 335.8 & 386.3 \\
\hline
\end{tabular}


TABIE 7. Table for calculating lactose hydrate and its mixtures with sucrose

\begin{tabular}{|c|c|c|c|}
\hline \multirow{2}{*}{ Copper } & \multirow{2}{*}{ Lactose $\cdot \mathrm{H}_{2} \mathrm{O}$} & \multicolumn{2}{|c|}{ Lactose $\cdot \mathrm{H}_{2} \mathrm{O}$ and sucrose } \\
\hline & & $\begin{array}{l}1 \text { lactose } \\
4 \text { sucrose }\end{array}$ & $\begin{array}{l}1 \text { lactose } \\
12 \text { sucrose }\end{array}$ \\
\hline$m g$ & $m g$ & $m g$ & $m g$ \\
\hline 10 & 7. 7 & 7.7 & 6.6 \\
\hline 11 & 8.5 & 8.5 & 7. 3 \\
\hline 12 & 9.3 & 9.2 & 8.0 \\
\hline 13 & 10.0 & 10.0 & 8.7 \\
\hline 14 & 10.8 & 10.7 & 9.4 \\
\hline 15 & 11.5 & 11.5 & 10.1 \\
\hline 16 & 12.3 & 12.2 & 10.8 \\
\hline 17 & 13.1 & 12.9 & 11.5 \\
\hline 18 & 13.8 & 13.7 & 12. 2 \\
\hline 19 & 14. 6 & 14.4 & 12.9 \\
\hline 20 & 15.4 & 15.2 & 13.6 \\
\hline 21 & 16.1 & 15.9 & 14.4 \\
\hline 22 & 16.9 & 16.7 & 15.1 \\
\hline 23 & 17. 7 & 17.4 & 15.8 \\
\hline 24 & 18.4 & 18.2 & 16.5 \\
\hline 25 & 19. 2 & 18.9 & 17. 2 \\
\hline 26 & 19.9 & 19.7 & 17. 9 \\
\hline 27 & 20.7 & 20.4 & 18.6 \\
\hline 28 & 21.5 & 21.1 & 19.3 \\
\hline 29 & 22.2 & 21.9 & 20.0 \\
\hline 30 & 23.0 & 22.6 & 20.7 \\
\hline 31 & 23.8 & 23.4 & 21.4 \\
\hline 32 & 24.5 & 24.1 & 22.2 \\
\hline 33 & 25.3 & 24.9 & 22.9 \\
\hline 34 & 26.1 & 25.6 & 23.6 \\
\hline 35 & 26.8 & 26.4 & 24.3 \\
\hline 36 & 27.6 & 27.1 & 25.0 \\
\hline 37 & 28.4 & 27.9 & 25.7 \\
\hline 38 & 29.1 & 28.6 & 26.4 \\
\hline 39 & 29.9 & 29.4 & 27.1 \\
\hline 40 & 30.6 & 30.1 & 27.8 \\
\hline 41 & 31.4 & 30.8 & 28.6 \\
\hline 42 & 32.2 & 31.6 & 29.3 \\
\hline 43 & 32.9 & 32.3 & 30.0 \\
\hline 44 & 33.7 & 33.1 & 30.7 \\
\hline 45 & 34.5 & 33.8 & 31.4 \\
\hline 46 & 35.2 & 34.6 & 32.1 \\
\hline 47 & 36.0 & 35.3 & 32.8 \\
\hline 48 & 36.8 & 36.1 & 33.5 \\
\hline 49 & 37.5 & 36.8 & 34.3 \\
\hline 50 & 38.3 & 37.6 & 35.0 \\
\hline 51 & 39.1 & 38.3 & 35.7 \\
\hline 52 & 39.8 & 39.1 & 36.4 \\
\hline 53 & 40.6 & 39.8 & 37.1 \\
\hline 54 & 41.4 & 40.6 & 37.8 \\
\hline 55 & 42.1 & 41.3 & 38.5 \\
\hline 56 & 42.9 & 42.1 & 39.3 \\
\hline 57 & 43.7 & 42.8 & 40.0 \\
\hline 58 & 44.4 & 43.6 & 40.7 \\
\hline 59 & 45.2 & 44. 3 & 41. 4 \\
\hline 60 & 46.0 & 45.1 & 42.1 \\
\hline 61 & 46.7 & 45.8 & 42.8 \\
\hline 62 & 47.5 & 46.5 & 43. 6 \\
\hline 63 & 48.3 & 47.3 & 44.3 \\
\hline 64 & 49.0 & 48.0 & 45.0 \\
\hline
\end{tabular}

TABLE 7. Table for calculating lactose hydrate and its mixtures with sucrose-Continued

\begin{tabular}{|c|c|c|c|}
\hline \multirow{2}{*}{ Copper } & \multirow{2}{*}{ Lactose $\cdot \mathrm{H}_{2} \mathrm{O}$} & \multicolumn{2}{|c|}{ Lactose $\cdot \mathrm{H}_{3} \mathrm{O}$ and sucrose } \\
\hline & & $\begin{array}{l}1 \text { lactose } \\
4 \text { sucrose }\end{array}$ & $\begin{array}{l}1 \text { lactose } \\
12 \text { sucrose }\end{array}$ \\
\hline$m g$ & $m g$ & $m g$ & $m g$ \\
\hline 65 & 49.8 & 48.8 & 45.7 \\
\hline 66 & 50.6 & 49.5 & 46.4 \\
\hline 67 & 51.3 & 50.3 & 47.1 \\
\hline 68 & 52.1 & 51.0 & 47.9 \\
\hline 69 & 52.9 & 51.8 & 48.6 \\
\hline 70 & 53.6 & 52.5 & 49.3 \\
\hline 71 & 54.4 & 53.3 & 50.0 \\
\hline 72 & 55.2 & 54.0 & 50.7 \\
\hline 73 & 55.9 & 54.8 & 51.4 \\
\hline 74 & 56.7 & 55.5 & 52.2 \\
\hline 75 & 57.5 & 56.3 & 52. 9 \\
\hline 76 & 58. 2 & 57.0 & 53.6 \\
\hline 77 & 59.0 & 57.8 & 54.3 \\
\hline 78 & 59.8 & 58.5 & 55.0 \\
\hline 79 & 60.5 & 59.3 & 55.7 \\
\hline 80 & 61.3 & 60.0 & 56.5 \\
\hline 81 & 62.1 & 60.8 & 57.2 \\
\hline 82 & 62.8 & 61.6 & 57.9 \\
\hline 83 & 63.6 & 62.3 & 58.6 \\
\hline 84 & 64.4 & 63.1 & 59.3 \\
\hline 85 & 65.1 & 63.8 & 60.1 \\
\hline 86 & 65.9 & 64.6 & 60.8 \\
\hline 87 & 66.7 & 65.3 & 61.5 \\
\hline 88 & 67.4 & 66.1 & 62.2 \\
\hline 89 & 68.2 & 66.8 & 62.9 \\
\hline 90 & 69.0 & 67.6 & 63.7 \\
\hline 91 & 69.7 & 68.3 & 64.4 \\
\hline 92 & 70.5 & 69.1 & 65.1 \\
\hline 93 & 71.3 & 69.8 & 65.8 \\
\hline 94 & 72.1 & 70.6 & 66.5 \\
\hline 95 & 72.8 & 71.3 & 67.3 \\
\hline 96 & 73.6 & 72.1 & 68.0 \\
\hline 97 & 74.4 & 72.8 & 68.7 \\
\hline 98 & 75.1 & 73.6 & 69.4 \\
\hline 99 & 75.9 & 74.3 & 70.2 \\
\hline 100 & 76.7 & 75.1 & 70.9 \\
\hline 101 & 77.4 & 75.8 & 71.6 \\
\hline 102 & 78. 2 & 76.6 & 72.3 \\
\hline 103 & 79.0 & 77.3 & 73.1 \\
\hline 104 & 79.7 & 78.1 & 73.8 \\
\hline 105 & 80.5 & 78.8 & 74.5 \\
\hline 106 & 81.3 & 79.6 & 75.2 \\
\hline 107 & 82.1 & 80.4 & 76.0 \\
\hline 108 & 82.8 & 81.1 & 76.7 \\
\hline 109 & 83.6 & 81.9 & 77.4 \\
\hline 110 & 84.4 & 82.6 & 78.1 \\
\hline 111 & 85.1 & 83.4 & 78.9 \\
\hline 112 & 85.9 & 84.1 & 79.6 \\
\hline 113 & 86.7 & 84.9 & 80.3 \\
\hline 114 & 87.4 & 85.6 & 81.0 \\
\hline 115 & 88.2 & 86.4 & 81.8 \\
\hline 116 & 89.0 & 87.1 & 82.5 \\
\hline 117 & 89.8 & 87.9 & 83.2 \\
\hline 118 & 90.5 & 88.6 & 84.0 \\
\hline 119 & 91.3 & 89.4 & 84.7 \\
\hline
\end{tabular}


TABLE 7. Table for calculating lactose hydrate and its mixtures with sucrose-Continued

\begin{tabular}{|c|c|c|c|}
\hline \multirow{2}{*}{ Copper } & \multirow{2}{*}{ Lactose $\cdot \mathrm{H}_{2} \mathrm{O}$} & \multicolumn{2}{|c|}{ Lactose $\cdot \mathrm{H}_{2} \mathrm{O}$ and sucrose } \\
\hline & & $\begin{array}{l}1 \text { lactose } \\
4 \text { sucrose }\end{array}$ & $\begin{array}{l}1 \text { lactose } \\
12 \text { sucrose }\end{array}$ \\
\hline$m g$ & $m g$ & $m g$ & $m g$ \\
\hline 120 & 92.1 & 90.2 & 85.4 \\
\hline 121 & 92.8 & 90.9 & 86.1 \\
\hline 122 & 93.6 & 91.7 & 86.9 \\
\hline 123 & 94.4 & 92.4 & 87.6 \\
\hline 124 & 95.2 & 93.2 & 88.3 \\
\hline 125 & 95.9 & 93.9 & 89.0 \\
\hline 126 & 96.7 & 94.7 & 89.8 \\
\hline 127 & 97.5 & 95.5 & 90.5 \\
\hline 128 & 98.2 & 96.2 & 91.2 \\
\hline 129 & 99.0 & 97.0 & 92.0 \\
\hline 130 & 99.8 & 97.7 & 92.7 \\
\hline 131 & 100.6 & 98.5 & 93.4 \\
\hline 132 & 101.3 & 99.2 & 94.1 \\
\hline 133 & 102.1 & 100.0 & 94.9 \\
\hline 134 & 102.9 & 100.7 & 95.6 \\
\hline 135 & 103.6 & 101.5 & 96.3 \\
\hline 136 & 104.4 & 102.3 & 97.1 \\
\hline 137 & 105. 2 & 103.0 & 97.8 \\
\hline 138 & 106.0 & 103.8 & 98.5 \\
\hline 139 & 106.7 & 104.5 & 99.3 \\
\hline 140 & 107.5 & 105.3 & 100.0 \\
\hline 141 & 108.3 & 106.0 & 100.7 \\
\hline 142 & 109.0 & 106.8 & 101.4 \\
\hline 143 & 109.8 & 107.5 & 102.2 \\
\hline 144 & 110.6 & 108.3 & 102.9 \\
\hline 145 & 111.4 & 109.1 & 103.6 \\
\hline 146 & 112.1 & 109.8 & 104.4 \\
\hline 147 & 112.9 & 110.6 & 105.1 \\
\hline 148 & 113.7 & 111.3 & 105.8 \\
\hline 149 & 114.4 & 112.1 & 106.6 \\
\hline 150 & 115. 2 & 112.8 & 107.3 \\
\hline 151 & 116.0 & 113.6 & 108.0 \\
\hline 152 & 116.8 & 114.4 & 108.8 \\
\hline 153 & 117.5 & 115.1 & 109.5 \\
\hline 154 & 118.3 & 115.9 & 110.2 \\
\hline 155 & 119.1 & 116.6 & 111.0 \\
\hline 156 & 119.9 & 117.4 & 111.7 \\
\hline 157 & 120.6 & 118. 2 & 112.4 \\
\hline 158 & 121.4 & 118.9 & 113.2 \\
\hline 159 & 122.2 & 119.7 & 113.9 \\
\hline 160 & 122.9 & 120.4 & 114.6 \\
\hline 161 & 123.7 & 121. 2 & 115.4 \\
\hline 162 & 124.5 & 121.9 & 116.1 \\
\hline 163 & 125.3 & 122.7 & 116.8 \\
\hline 164 & 126.0 & 123.5 & 117.6 \\
\hline 165 & 126.8 & 124. 2 & 118.3 \\
\hline 166 & 127.6 & 125.0 & 119.1 \\
\hline 167 & 128.4 & 125. 7 & 119.8 \\
\hline 168 & 129.1 & 126.5 & 120.5 \\
\hline 169 & 129.9 & 127.3 & 121.3 \\
\hline 170 & 130.7 & 128.0 & 122.0 \\
\hline 171 & 131.5 & 128.8 & 122.7 \\
\hline 172 & 132.2 & 129.5 & 123.5 \\
\hline 173 & 133.0 & 130.3 & 124. 2 \\
\hline 174 & 133.8 & 131.1 & 124.9 \\
\hline
\end{tabular}

TABLE 7. Table for calculating lactose hydrate and its mixtures with sucrose-Continued

\begin{tabular}{|c|c|c|c|}
\hline \multirow{2}{*}{ Copper } & \multirow{2}{*}{ Lactose $\cdot \mathrm{H}_{2} \mathrm{O}$} & \multicolumn{2}{|c|}{ Lactose $\cdot \mathrm{H}_{2} \mathrm{O}$ and sucrose } \\
\hline & & $\begin{array}{l}1 \text { lactose } \\
4 \text { sucrose }\end{array}$ & $\begin{array}{l}1 \text { lactose } \\
12 \text { sucrose }\end{array}$ \\
\hline$m g$ & $m g$ & $m g$ & $m g$ \\
\hline 175 & 134.6 & 131.8 & 125.7 \\
\hline 176 & 135.3 & 132.6 & 126.4 \\
\hline 177 & 136.1 & 133.4 & 127. 2 \\
\hline 178 & 136.9 & 134.1 & 127.9 \\
\hline 179 & 137.7 & 134.9 & 128.6 \\
\hline 180 & 138.4 & 135.6 & 129.4 \\
\hline 181 & 139. 2 & 136.4 & 130.1 \\
\hline 182 & 140.0 & 137.2 & 130.8 \\
\hline 183 & 140.8 & 137.9 & 131.6 \\
\hline 184 & 141.5 & 138.7 & 132.3 \\
\hline 185 & 142.3 & 139.4 & 133.1 \\
\hline 186 & 143.1 & 140.2 & 133.8 \\
\hline 187 & 143.9 & 141.0 & 134.5 \\
\hline 188 & 144.6 & 141.7 & 135.3 \\
\hline 189 & 145.4 & 142.5 & 136.0 \\
\hline 190 & 146. 2 & 143.3 & 136.8 \\
\hline 191 & 147.0 & 144.0 & 137.5 \\
\hline 192 & 147.7 & 144.8 & 138. 2 \\
\hline 193 & 148.5 & 145.5 & 139.0 \\
\hline 194 & 149.3 & 146.3 & 139.7 \\
\hline 195 & 150.1 & 147.1 & 140.5 \\
\hline 196 & 150.8 & 147.8 & 141. 2 \\
\hline 197 & 151.6 & 148.6 & 142.0 \\
\hline 198 & 152.4 & 149.3 & 142.7 \\
\hline 199 & 153.2 & 150.1 & 143.4 \\
\hline 200 & 153.9 & 150.9 & 144. 2 \\
\hline 201 & 154.7 & 151.6 & 144.9 \\
\hline 202 & 155.5 & 152.4 & 145.7 \\
\hline 203 & 156.3 & 153.2 & 146.4 \\
\hline 204 & 157.0 & 153.9 & 147.1 \\
\hline 205 & 157.8 & 154.7 & 147.9 \\
\hline 206 & 158.6 & 155.5 & 148.6 \\
\hline 207 & 159.4 & 156.2 & 149.4 \\
\hline 208 & 160.2 & 157.0 & 150.1 \\
\hline 209 & 160.9 & 157.7 & 150.9 \\
\hline 210 & 161.7 & 158.5 & 151.6 \\
\hline 211 & 162.5 & 159.3 & 152.4 \\
\hline 212 & 163.3 & 160.0 & 153.1 \\
\hline 213 & 164.0 & 160.8 & 153.8 \\
\hline 214 & 164.8 & 161.6 & 154.6 \\
\hline 215 & 165.6 & 162.3 & 155.3 \\
\hline 216 & 166.4 & 163.1 & 156.1 \\
\hline 217 & 167.1 & 163.9 & 156.8 \\
\hline 218 & 167.9 & 164.6 & 157.6 \\
\hline 219 & 168.7 & 165.4 & 158.3 \\
\hline 220 & 169.5 & 166. 2 & 159.1 \\
\hline 221 & 170.3 & 166.9 & 159.8 \\
\hline 222 & 171.0 & 167.7 & 160.6 \\
\hline 223 & 171.8 & 168.5 & 161.3 \\
\hline 224 & 172.6 & 169.2 & 162.1 \\
\hline 225 & 173.4 & 170.0 & 162.8 \\
\hline 226 & 174. 2 & 170.8 & 163.6 \\
\hline 227 & 174.9 & 171.5 & 164.3 \\
\hline 228 & 175.7 & 172.3 & 165.1 \\
\hline 229 & 176.5 & 173.1 & 165.8 \\
\hline
\end{tabular}


TABLE 7. Table for calculating lactose hydrate and its mixtures with sucrose - Continued

\begin{tabular}{|c|c|c|c|}
\hline \multirow{2}{*}{ Copper } & \multirow{2}{*}{ Lactose $\cdot \mathrm{H}_{2} \mathrm{O}$} & \multicolumn{2}{|c|}{ Lactose $\cdot \mathrm{H}_{2} \mathrm{O}$ and sucrose } \\
\hline & & $\begin{array}{l}1 \text { lactose } \\
4 \text { sucrose }\end{array}$ & $\begin{array}{l}1 \text { lactose } \\
12 \text { sucrose }\end{array}$ \\
\hline$m g$ & $m g$ & $m g$ & $m g$ \\
\hline 230 & 177.3 & 173.8 & 166.5 \\
\hline 231 & 178.1 & 174.6 & 167.3 \\
\hline 232 & 178.8 & 175.3 & 168.0 \\
\hline 233 & 179.6 & 176.1 & 168.8 \\
\hline 234 & 180.4 & 176. 9 & 169.5 \\
\hline 235 & 181. 2 & 177.6 & 170.3 \\
\hline 236 & 181.9 & 178.4 & 171.0 \\
\hline 237 & 182.7 & 179.2 & 171.8 \\
\hline 238 & 183.5 & 180.0 & 172.5 \\
\hline 239 & 184.3 & 180.7 & 173.3 \\
\hline 240 & 185.1 & 181.5 & 174. 0 \\
\hline 241 & 185.8 & 182.3 & 174.8 \\
\hline 242 & 186.6 & 183.0 & 175.5 \\
\hline 243 & 187.4 & 183.8 & 176.3 \\
\hline 244 & 188.2 & 184.6 & 177.0 \\
\hline 245 & 189.0 & 185.3 & 177.8 \\
\hline 246 & 189.7 & 186.1 & 178.5 \\
\hline 247 & 190.5 & 186.9 & 179.3 \\
\hline 248 & 191.3 & 187.6 & 180.1 \\
\hline 249 & 192.1 & 188.4 & 180.8 \\
\hline 250 & 192.9 & 189.2 & 181.6 \\
\hline 251 & 193.6 & 189.9 & 182. 3 \\
\hline 252 & 194.4 & 190.7 & 183.1 \\
\hline 253 & 195. 2 & 191.5 & 183.8 \\
\hline 254 & 196.0 & 192. 2 & 184.6 \\
\hline 255 & 196.8 & 193.0 & 185.3 \\
\hline 256 & 197.5 & 193.8 & 186. 1 \\
\hline 257 & 198.3 & 194.6 & 186.8 \\
\hline 258 & 199.1 & 195.3 & 187.6 \\
\hline 259 & 199.9 & 196.1 & 188.3 \\
\hline 260 & 200.7 & 196.9 & 189.1 \\
\hline 261 & 201.4 & 197.6 & 189.8 \\
\hline 262 & 202.2 & 198.4 & 190.6 \\
\hline 263 & 203.0 & 199. 2 & 191.4 \\
\hline 264 & 203.8 & 199.9 & 192.1 \\
\hline 265 & 204.6 & 200.7 & 192.9 \\
\hline 266 & 205. 3 & 201.5 & 193.6 \\
\hline 267 & 206.1 & 202.2 & 194.4 \\
\hline 268 & 206.9 & 203.0 & 195.1 \\
\hline 269 & 207.7 & 203.8 & 195.9 \\
\hline 270 & 208.5 & 204.6 & 196. 7 \\
\hline 271 & 209. 2 & 205.3 & 197.4 \\
\hline 272 & 210.0 & 206.1 & 198.2 \\
\hline 273 & 210.8 & 206.9 & 198.9 \\
\hline 274 & 211.6 & 207.6 & 199.7 \\
\hline 275 & 212.4 & 208.4 & 200.4 \\
\hline 276 & 213. 2 & 209. 2 & 201.2 \\
\hline 277 & 214.0 & 210.0 & 202.0 \\
\hline 278 & 214.7 & 210.7 & 202.7 \\
\hline 279 & 215.5 & 211. 5 & 203.5 \\
\hline 280 & 216.3 & 212. 3 & 204.2 \\
\hline 281 & 217.1 & 213.0 & 205.0 \\
\hline 282 & 217.9 & 213.8 & 205.7 \\
\hline 283 & 218.7 & 214. 6 & 206.5 \\
\hline 284 & 219.4 & 215.4 & 207.3 \\
\hline
\end{tabular}

TABLE 7. Table for calculating lactose hydrate and its mixtures with sucrose-Continued

\begin{tabular}{|c|c|c|c|}
\hline \multirow{2}{*}{ Copper } & \multirow{2}{*}{ Lactose $\cdot \mathrm{H}_{2} \mathrm{O}$} & \multicolumn{2}{|c|}{ Lactose $\cdot \mathrm{H}_{2} \mathrm{O}$ and sucrose } \\
\hline & & $\begin{array}{l}1 \text { lactose } \\
4 \text { sucrose }\end{array}$ & $\begin{array}{l}1 \text { lactose } \\
12 \text { sucrose }\end{array}$ \\
\hline$m g$ & $m g$ & $m g$ & $m g$ \\
\hline 285 & 220.2 & 216. 1 & 208.0 \\
\hline 286 & 221.0 & 216.9 & 208.8 \\
\hline 287 & 221.8 & 217.7 & 209.5 \\
\hline 288 & 222.6 & 218.4 & 210.3 \\
\hline 289 & 223.3 & 219.2 & 211.1 \\
\hline 290 & 224.1 & 220.0 & 211.8 \\
\hline 291 & 224.9 & 220.8 & 212.6 \\
\hline 292 & 225.7 & 221.5 & 213.4 \\
\hline 293 & 226.5 & 222.3 & 214.1 \\
\hline 294 & 227.3 & 223.1 & 214.9 \\
\hline 295 & 228.0 & 223.9 & 215.6 \\
\hline 296 & 228.8 & 224.6 & 216.4 \\
\hline 297 & 229.6 & 225.4 & 217.2 \\
\hline 298 & 230.4 & 226.2 & 217.9 \\
\hline 299 & 231. 2 & 227.0 & 218.7 \\
\hline 300 & 232.0 & 227.7 & 219.5 \\
\hline 301 & 232.7 & 228.5 & 220.2 \\
\hline 302 & 233.5 & 229.3 & 221.0 \\
\hline 303 & 234.3 & 230.1 & 221.7 \\
\hline 304 & 235.1 & 230.8 . & 222.5 \\
\hline 305 & 235.9 & 231.6 & 223.3 \\
\hline 306 & 236.7 & 232.4 & 224.0 \\
\hline 307 & 237.4 & 233.1 & 224.8 \\
\hline 308 & 238.2 & 233.9 & 225.6 \\
\hline 309 & 239.0 & 234.7 & 226.3 \\
\hline 310 & 239.8 & 235.5 & 227.1 \\
\hline 311 & 240.6 & 236.3 & 227.9 \\
\hline 312 & 241.4 & 237.0 & 228.6 \\
\hline 313 & 242.2 & 237.8 & 229.4 \\
\hline 314 & 243.0 & 238.6 & 230.2 \\
\hline 315 & 243.7 & 239.4 & 230.9 \\
\hline 316 & 244.5 & 240.1 & 231.7 \\
\hline 317 & 245.3 & 240.9 & 232.5 \\
\hline 318 & 246.1 & 241.7 & 233.2 \\
\hline 319 & 246.9 & 242.5 & 234.0 \\
\hline 320 & 247.7 & 243.2 & 234.8 \\
\hline 321 & 248.5 & 244.0 & 235.5 \\
\hline 322 & 249.2 & 244.8 & 236.3 \\
\hline 323 & 250.0 & 245.6 & 237.1 \\
\hline 324 & 250.8 & 246.3 & 237.8 \\
\hline 325 & 251.6 & 247.1 & 238.6 \\
\hline 326 & 252.4 & 247.9 & 239.4 \\
\hline 327 & 253.2 & 248.7 & 240.1 \\
\hline 328 & 253.9 & 249.5 & 240.9 \\
\hline 329 & 254.7 & 250.2 & 241.7 \\
\hline 330 & 255.5 & 251.0 & 242.4 \\
\hline 331 & 256.3 & 251.8 & 243.2 \\
\hline 332 & 257.1 & 252.6 & 244.0 \\
\hline 333 & 257.9 & 253.3 & 244.8 \\
\hline 334 & 258.7 & 254.1 & 245.5 \\
\hline 335 & 259.4 & 254.9 & 246.3 \\
\hline 336 & 260.2 & 255.7 & 247.1 \\
\hline 337 & 261.0 & 256.5 & 247.8 \\
\hline 338 & 261.8 & 257.2 & 248.6 \\
\hline 339 & 262.6 & 258.0 & 249.4 \\
\hline
\end{tabular}


TABLE 7. Table for calculating lactose hydrate and its mixtures with sucrose-Continued

\begin{tabular}{|c|c|c|c|}
\hline \multirow{2}{*}{ Copper } & \multirow{2}{*}{ Lactose $\mathrm{H}_{3} \mathrm{O}$} & \multicolumn{2}{|c|}{ Lactose $\mathrm{H}_{3} \mathrm{O}$ and sucrose } \\
\hline & & $\begin{array}{l}1 \text { lactose } \\
4 \text { suerose }\end{array}$ & $\begin{array}{l}\text { a lactose } \\
12 \text { suerose }\end{array}$ \\
\hline$m g$ & $m g$ & $m g$ & $m g$ \\
\hline 340 & 263.4 & 258.8 & 250.2 \\
\hline 341 & 264. 2 & 259.6 & 250.9 \\
\hline 342 & 265.0 & 260.4 & 251. 7 \\
\hline 343 & 265.8 & 261.1 & 252.5 \\
\hline 344 & 266.6 & 261.9 & 253.3 \\
\hline 345 & 267.4 & 262.7 & 254.0 \\
\hline 346 & 268.1 & 263.5 & 254.8 \\
\hline 347 & 268.9 & 264. 2 & 255.6 \\
\hline 348 & 269.7 & 265.0 & 256.4 \\
\hline 349 & 270.5 & 265.8 & 257.1 \\
\hline 350 & 271.3 & 266.6 & 257.9 \\
\hline 351 & 272.1 & 267.4 & 258.7 • \\
\hline 352 & 272.9 & 268.2 & 259.4 \\
\hline 353 & 273.7 & 268.9 & 260.2 \\
\hline 354 & 274.4 & 269.7 & 261.0 \\
\hline 355 & 275.2 & 270.5 & 261.8 \\
\hline 356 & 276.0 & 271.3 & 262.6 \\
\hline 357 & 276.8 & 272.1 & 263.3 \\
\hline 358 & 277.6 & 272.8 & 264.1 \\
\hline 359 & -278.4 & 273.6 & 264.9 \\
\hline 360 & 279.2 & 274.4 & 265.7 \\
\hline 361 & 280.0 & 275. 2 & 266.4 \\
\hline 362 & 280.8 & 276.0 & 267.2 \\
\hline 363 & 281.6 & 276.8 & 268.0 \\
\hline 364 & 282.4 & 277.5 & 268.8 \\
\hline 365 & 283.2 & 278.3 & 269.6 \\
\hline 366 & 284.0 & 279.1 & 270.3 \\
\hline 367 & 284.8 & 279.9 & 271.1 \\
\hline 368 & 285.6 & 280.7 & 271.9 \\
\hline 369 & 286.3 & 281.5 & 272.7 \\
\hline 370 & 287.1 & 282. 2 & 273.5 \\
\hline 371 & 287.9 & 283.0 & 274.2 \\
\hline 372 & 288.7 & 283.8 & 275.0 \\
\hline 373 & 289.5 & 284.6 & 275.8 \\
\hline 374 & 290.3 & 285.4 & 276.6 \\
\hline 375 & 291.1 & 286.2 & 277.4 \\
\hline 376 & 291.9 & 286.9 & 278.2 \\
\hline 377 & 292.7 & 287.7 & 278.9 \\
\hline 378 & 293.5 & 288.5 & 279.7 \\
\hline 379 & 294.3 & 289.3 & 280.5 \\
\hline 380 & 295.0 & 290.1 & 281.3 \\
\hline 381 & 295.8 & 290.9 & 282.1 \\
\hline 382 & 296.6 & 291. 7 & 282.9 \\
\hline 383 & 297.4 & 292.4 & 283.6 \\
\hline 384 & 298.2 & 293. 2 & 284.4 \\
\hline 385 & 299.0 & 294.0 & 285.2 \\
\hline 386 & 299.8 & 294.8 & 286.0 \\
\hline 387 & 300.6 & 295.6 & 286.8 \\
\hline 388 & 301.4 & 296.4 & 287.6 \\
\hline 389 & 302.2 & 297. 2 & 288.4 \\
\hline
\end{tabular}

TABLE 7. Table for calculating lactose hydrate and its mixtures with sucrose-Continued

\begin{tabular}{|c|c|c|c|}
\hline \multirow{2}{*}{ Copper } & \multirow{2}{*}{ Lactose $\mathrm{H}_{3} \mathrm{O}$} & \multicolumn{2}{|c|}{ Lactose $\mathrm{H}_{3} \mathrm{O}$ and sucrose } \\
\hline & & $\begin{array}{l}1 \text { lactose } \\
4 \text { sucrose }\end{array}$ & $\begin{array}{l}\text { a lactose } \\
12 \text { sucrose }\end{array}$ \\
\hline$m g$ & $m g$ & $m g$ & $m g$ \\
\hline 390 & 303.0 & 298.0 & 289. 2 \\
\hline 391 & 303.8 & 298.8 & 290.0 \\
\hline 392 & 304.6 & 299.5 & 290.7 \\
\hline 393 & 305.4 & 300.3 & 291.5 \\
\hline 394 & 306.2 & 301.1 & 292.3 \\
\hline 395 & 307.0 & 301.9 & 293.1 \\
\hline 396 & 307.8 & 302.7 & 293.9 \\
\hline 397 & 308.6 & 303.5 & 294.7 \\
\hline 398 & 309.4 & 304.3 & 295.5 \\
\hline 399 & 310.2 & 305.1 & 296. 3 \\
\hline 400 & 311.0 & 305.9 & 297.1 \\
\hline 401 & 311.8 & 306.7 & 297. 9 \\
\hline 402 & 312.6 & 307.5 & 298.7 \\
\hline 403 & 313.4 & 308.3 & 299.5 \\
\hline 404 & 314.2 & 309.1 & 300.3 \\
\hline 405 & 315.0 & 309.9 & 301.1 \\
\hline 406 & 315.9 & 310.7 & 301.9 \\
\hline 407 & 316.7 & 311.5 & 302.7 \\
\hline 408 & 317.5 & 312.3 & 303.5 \\
\hline 409 & 318.3 & 313.1 & 304.3 \\
\hline 410 & 319.1 & 313.9 & 305.1 \\
\hline 411 & 319.9 & 314.7 & 305.9 \\
\hline 412 & 320.7 & 315.5 & 306.7 \\
\hline 413 & 321.6 & 316.3 & 307.6 \\
\hline 414 & 322.4 & 317.1 & 308.4 \\
\hline 415 & 323.2 & 317.9 & 309.2 \\
\hline 416 & 324.0 & 318.7 & 310.0 \\
\hline 417 & 324.9 & 319.5 & 310.8 \\
\hline 418 & 325.7 & 320.3 & 311.7 \\
\hline 419 & 326.5 & 321.2 & 312.5 \\
\hline 420 & 327.4 & 322.0 & 313.4 \\
\hline 421 & 328. 2 & 322.8 & 314. 2 \\
\hline 422 & 329.1 & 323.6 & 315.0 \\
\hline 423 & 329. 9 & 324.5 & 315.9 \\
\hline 424 & 330.8 & 325.3 & 316.8 \\
\hline 425 & 331. 7 & 326.2 & 317.6 \\
\hline 426 & 332.6 & 327.0 & 318.5 \\
\hline 427 & 333.5 & 327.9 & 319.4 \\
\hline 428 & 334. 4 & 328.8 & 320.4 \\
\hline 429 & 335. 3 & 329.7 & 321.3 \\
\hline 430 & 336. 3 & 330.6 & 322.3 \\
\hline 431 & 337.3 & 331.5 & 323. 3 \\
\hline 432 & 338. 3 & 332.5 & 324.4 \\
\hline 433 & 339.4 & 333.5 & 325.5 \\
\hline 434 & 340.7 & 334.6 & 326.7 \\
\hline 435 & 342.0 & 335.8 & 328.1 \\
\hline
\end{tabular}


Since there was a controversy over the composition of the lactose prepared by Walker, and since the author has discovered the Straughn-Given table for the lactose-sucrose ratio of $1: 12$ to be in error, it was felt that the results reported in this paper should not depend solely on the work of one individual. So the author has determined the reducing value of the lactose used by McDonald and Turcotte [16] in their work on the density and refractive index of lactose solutions and found it to be identical with that of his preparation. J. F. Brewster of this Bureau also prepared a sample of pure lactose and found its reducing power to be the same as that of McDonald and Turcotte and that of the author. In addition, he kindly checked several values in the experimental data given in table 2 . His results are shown in table 6 and are self-explanatory.

\section{References}

[1] L. S. Munson and P. H. Walker, J. Am. Chem. Soc. 28, 663 (1906).

[2] P. H. Walker, J. Am. Chem. Soc. 29, 541 (1907).

[3] P. H. Walker, J. Am. Chem. Soc. 34, 202 (1912).

[4] A. Given, Methods for Sugar Analysis, p. 52 (P. Blakiston's Son and Co., Phila., Pa., 1912).
[5] H. T. Brown, G. H. Morris, and J. H. Millar, J. Chem. Soc. Trans. 71, 76 (1897).

[6] E. O. Von Lippman, Die Chemie der Zuckerarten, 3 Auflage, 1526 (1904).

[7] F. A. Quisumbing and A. W. Thomas, J. Am. Chem. Soc. 43, 1503 (1921).

[8] J. H. Lane and L. Eynon, J. Soc. Chem. Ind. 42, $34 \mathrm{~T}$ (1923).

[9] G. Bertrand, Bul. Soc. Chim. 35, 1285 (1906).

[10] M. Schmoeger, Ber. chem. Ges. 13, 1922 (1880).

[11] M. G. Deniges and E. Bonvans, J. pharm. chim. [5] 17, 363 (1888).

[12] E. Parcus and B. Tollens, Liebigs Ann. Chem. 257, 160 (1890).

[13] A. L. Bacharach, Analyst 48, 521 (1923).

[14] H. Grossman and F. L. Bloch, Z. Ver. deut. Zuck-Ind. [Tech. Teil.] 62, 61 (1912)

[15] C. S. Hudson, The Princeton Univ. Bul. 13, 62 (1902).

[16] E. J. McDonald and A. L. Turcotte, J. Research NBS 41, 63 (1948) RP1904.

[17] L. S. Munson, Bur. Chem. Bul. 73, 59 (1902).

[18] F. W. Zerban and W. P. Naquin, J. Am. Chem. Soc. 30, 1456 (1908).

[19] W. O. Snelling, J. Am. Chem. Soc. 31, 456 (1909).

[20] L. D. Hammond, J. Research NBS 24, 579 (1940) RP1301.

[21] R. F. Jackson and E. J. McDonald, J. Research NBS 27, 237 (1941) RP1417.

[22] W. B. White, Bul. 234, New York State Department of Agriculture and Markets (1930).

[23] J. Fitelson, J. Assoc. Agr. Chem. 15, 624 (1932).

Washington, March 1, 1948. 